\title{
Em Busca do Passado: Memórias e Identidade do lugar
}

\author{
In Search of the Past: Memories and Place's Identity
}

En Busca del Pasado: Memoria e Identidad del lugar

Letycia Alves de Macêdo ${ }^{1}$

Dr. Leandro Roberto Neves ${ }^{2}$

\begin{abstract}
Resumo
O presente estudo é um projeto de iniciação científica vinculada à pesquisa "Fronteiras e Amazônia: Aspectos urbanos e representações citadinas, realizada na cidade de Boa Vista-Roraima-Brasil". Tal subprojeto analisou aspectos do processo de formação da identidade social de lugar e memória social de uma moradora migrante de Fortaleza-CE para a capital do Estado de Roraima. Utilizou-se de um referencial teórico indisciplinar e uma orientação metodológica baseada na história oral. Como instrumento se utilizou entrevista aberta, na qual podese identificar elementos subjetivos e objetivos emergidos na relação ambiente/pessoa substanciais para a compreensão da permanência/pertencimento da depoente na cidade de Boa Vista. Todos os procedimentos éticos de pesquisa com seres humanos foram respeitados. Como resultado percebeu-se uma valorização das duas capitais na memória da entrevistada e uma transição na relação de pertencimento de um lugar para o outro, considerando para tal entendimento a categoria de apego e permanência desenvolvida na Psicologia Ambiental. Nesse contexto, a identidade de lugar sofreu mediações de elementos materiais e imateriais, tais como: a casa própria, a família, o trabalho, os quais têm como hipótese que resignificaram a relação ambiente/pessoa da depoente.
\end{abstract}

Palavras-Chave: Categoria, cidade, identidade de lugar, memória

\section{Resumen}

Este estudio es un proyecto de investigación relacionado con el estudio "Borders y Amazonas aspectos urbanos y las representaciones de la ciudad, que se celebró en la ciudad de Boa Vista, Roraima, Brasil." Este subproyecto analizó los aspectos del proceso de formación de la identidad social del lugar y la memoria social de un migrante que vive en Fortaleza a la capital del estado de Roraima. Se utilizó una orientación teórica y metodológica indisciplinary basado en la historia oral. Como se utilizó un instrumento de entrevista abierta, en la que uno puede identificar y elementos subjetivos surgido goles en relación ambiente / persona importante para entender la permanencia / perteneciente al declarante en la ciudad de Boa Vista. Se han respetado todos los procedimientos éticos para la investigación en seres humanos. Como resultado de ello se realizó una apreciación de las dos capitales en la memoria del entrevistado y una transición en relación pertenencia de un lugar a otro, considerando para la categoría de fijación comprensión y permanencia desarrollados en la psicología ambiental. En este contexto, el lugar de la identidad sufrió mediaciones de elementos tangibles e intangibles, tales como el hogar, la familia, el trabajo, los cuales tienen la hipótesis de que la resinificaram / persona declarante relación medio ambiente.

Palabras claves: Ciudad, categoría, lugar de identidad, memoria.

1 Universidade Federal de Roraima - Universidade Federal de Roraima - UFRR, Boa Vista, Roraima, Brasil. letyciaalves702@gmail.com

${ }^{2}$ Doutorado em Psicologia Social; Universidade Federal de Roraima - UFRR, Boa Vista, Roraima, Brasil. leandro.neves@ufrr.br 


\begin{abstract}
The present study is a scientific research of a project linked with "Borders and Amazon urban aspects and city representations, held in the city of Boa Vista, Roraima, Brazil." On this subproject analyzed aspects of the process of formation of the social identity of place and social memory of a migrant who lives in Fortaleza to the capital of the State of Roraima. It used as indisciplinary theoretical and methodological guidance based on oral history. As an instrument was used to an open interview, in which one can identify and subjective elements emerged goals in relation environment / substantial person to understand the permanence / belonging to the deponents in the city of Boa Vista. All ethical procedures for research involving human beings were respected. As a result it was realized to an appreciation of the two capitals in memory of the interviewee and a transition in belonging relationship from one place to another, considering for such understanding attachment category and permanence developed in environmental psychology. In this context, the place of identity suffered mediations of tangible and intangible elements, such as the home, family, work, which have hypothesized that resignated the environment relationship / people deponents.
\end{abstract}

Keywords: Category, city, place identity, memory.

\title{
1. Introdução
}

O homem é visto como um ser social, que se relaciona sempre com o outro. Sendo constituído e constituinte das relações, ele age no ambiente ${ }^{3}$ tornando-se, assim, agente e ao mesmo tempo o reflexo das transformações que o meio sofre. Existe uma relação mútua entre o homem e o ambiente, que pode ser vista como uma cadeia contínua, em que as mudanças acarretam outras, sem chegar a uma parada/fim. Essa relação acontece das mais variadas formas e abre caminho para o desenvolvimento das categorias que o estudo objetiva identificar na história apresentada pela entrevistada.

A ocupação dos lugares ${ }^{4}$ acontece a partir de uma necessidade do(s) indivíduo(s). Seja ela a moradia, o acolhimento, o apoio social, etc. Existe uma seleção do sujeito para ocupar o espaço que mais lhe convém e/ou atenda as suas necessidades, atribuindo a ele marcas e impressões visíveis (físicas e sociais) que transformam o meio em um "lugarzinho seu" (CAVALCANTE \& ELIAS, 2011).

É importante entender o ambiente como algo não vazio, ele carrega consigo os traços do domínio exercido pelo sujeito. O relacionamento homem-ambiente existe em conformidade com a ocupação do espaço (NEVES, 2016). Através dessa relação é possível atribuir uma "tonalidade afetiva"5 ao lugar e todas as relações que são estabelecidas nesse

\footnotetext{
${ }^{3}$ É necessário entender o conceito de ambiente como "[...] o meio físico concreto em que se vive, natural ou construído, o qual é indissociável das condições sociais, econômicas, políticas, culturais e psicológicas daquele contexto específico" (CAMPOS-DE-CARVALHO, CAVALCANTE \& NÓBREGA, 2011,p.28).

${ }^{4} \mathrm{O}$ sujeito passa, então, a relacionar-se com o meio em que está. Esse relacionamento influencia a existência do processo de apropriação do homem em relação ao ambiente (CARLOS, 2009 apud ALVES, 2015, p.11).

${ }^{5}$ Segundo Tuan (2013) conforme é atribuída uma "tonalidade afetiva" a um ambiente, este passa a representar algo para o sujeito.
} 
ambiente. Os afetos promovem as ações na vida e influenciam as percepções que a pessoa tem das situações da vida, impulsionando certas reações (BOCK \& FURTADO, 2008). Colaboram na construção de processos de identidade de lugar, o apego ao lugar e o sentimento de pertencimento.

Conforme for sendo atribuída uma "tonalidade afetiva" a um ambiente, este passa a representar algo para o sujeito. Nesse processo, o ambiente que no início era um "espaço", torna-se um "lugar", na medida em que passa a carregar uma significação afetiva. Em reconhecimento a relevância desses três aspectos na relação indivíduo-ambiente, eles serão usados para apontar tais processos na história de vida de uma moradora de Boa Vista, Roraima. Os conceitos tratados acima servirão como base para influenciar o processo de apego ao lugar, identidade de lugar e sentimento de pertencimento.

Desta forma, a pesquisa é de cunho descritivo e possui abordagem qualitativa. Em virtude das demandas do objeto de estudo utilizou-se o método de história oral. Pois, este, permite recortes e colagens de fatos passados na voz daqueles que vivenciaram o fenômeno. Produzindo, assim, reflexões e um conhecimento sobre algo em que se consideram as particularidades do ambiente físico e social.

O estudo foi realizado com uma pessoa do sexo feminino. A depoente mora em Boa Vista por, aproximadamente, 34 anos.

Segundo Bosi (1994) a narrativa constituinte da autobiografia é o único meio pelo qual se pode conhecer a memória de uma pessoa. E, diante disto, optou-se pelo uso da entrevista aberta para instrumentalizar o método e colher as informações. E através dela tivemos a possibilidade de registrar aspectos relevantes à moradora da cidade de Boa Vista através de sua respectiva visão sobre a memória do passado.

Portanto, a história oral mostrou-se importante na medida em que permitiu uma reconstrução do passado da depoente através de seu método (FREITAS, 2006). Produzindo registro, material científico e documentos que mostrem uma visão do passado a partir do presente. Criando assim recortes e justificativas do passado amparado pela visão do presente da depoente partindo de um contexto e particularidades específicas do sujeito.

O procedimento aconteceu em momentos. Sendo o primeiro a seleção dos depoentes para a entrevista. A escolha da entrevistada não foi aleatória. Foi contatada a partir de uma busca por pessoas que correspondesse aos critérios e tivesse interesse em participar do estudo. O contato foi feito por ligação via telefone e após a confirmação do interesse em participar, marcamos a data e o local para realizar a entrevista. Houve dificuldades para a localização de mais de um depoente, pois as pessoas que foram propostas no início apresentaram não 
interesse ou alguma dificuldade. Preferindo não participar do estudo. Em função desse problema realizamos a entrevista com uma depoente.

No dia e local marcado apresentamos o projeto, objetivos do projeto e o Termo de Consentimento Livre e Esclarecido (TCLE) a participante do projeto. Assim como, também, foram esclarecidas as dúvidas da pesquisa. Foi informado, ainda, que a participação implicou em atividade não remunerada e poderia desistir a qualquer momento que não estivesse se sentindo à vontade para prosseguir com as etapas da pesquisa. Foram garantidos ainda sigilo e confidencialidade das informações fornecidas pela participante.

Após a assinatura do TCLE, realizou-se a entrevista aberta e o registro se deu por meio de um gravador digital sem imagem. Quando a entrevista acabou foram feitos alguns esclarecimentos sobre o projeto e agradecimentos pela contribuição no estudo. O registro da fala foi realizado pela transcrição do áudio e a partir dela se iniciou a análise.

A partir da análise e discussões da entrevista discutiremos as categorias de identidade de lugar, sentimento de pertencimento e memória a partir do registro de uma entrevista feita com Rosa Maria, nascida em Fortaleza, Ceará, no dia dez de maio de 1964. Ela vive na cidade de Boa Vista há aproximadamente 34 anos e, atualmente com 52 anos, ela reside em casa própria com sua mãe e seus dois filhos.

No intuito de alcançar o objetivo proposto, o qual se configura em discutir as categorias já mencionadas, não seguiremos de forma linear a exposição dos assuntos abordados e análise da história de vida de dona Rosa, pois acreditamos que uma noção pressupõe a outra e ao passo que ela aparecer, será abordado.

Importa mencionar alguns apontamentos de análise sobre a experiência de vida da entrevistada, a qual teve vivências e experiências nas duas cidades e em outros lugares. A partir disso, foi criada certa vinculação que permitiu determinados processos de análise do estudo. Entretanto, a forma como viveu nas cidades esteve ligada a um contexto de ordem social, cultural, econômico, físico, emocional e outros específicos. Diante disso, as cidades apresentadas foram vivenciadas em partes, em recortes, em contextos específicos ao sujeito. De acordo com Lynch (1997) a percepção que temos da cidade não abrange a sua totalidade ou uma parte significativa a todos. Ela é vivida de forma parcial, fragmentada e em contato com diversos elementos que em conjunto permitem ao sujeito formar uma imagem da cidade através da percepção que tem dela.

O estudo não visa, em sua explanação, à separação de elementos que caracterizem unicamente uma determinada classificação, pelo motivo de não acreditarmos nessa possibilidade, visto que os elementos podem estar presentes em mais de uma categoria 
apresentada. Desta forma, é possível que venha aparecer elementos parecidos ou até repetitivos nas classificações, em vista da abrangência e congruência que há entre as categorias.

Ao iniciar a entrevista, foi observada a grande afeição que Rosa demonstrou sentir por Fortaleza. Entretanto, ela aponta não querer morar lá novamente, limitando-se a viajar esporadicamente a passeio para sua cidade, pois prefere morar onde reside no momento, conforme Rosa afirmou: "Olha, Fortaleza é maravilhoso (sic). As praias lindas. Mas eu não troco mais. Eu prefiro morar em Boa Vista" (MARIA, 2016, p.1). Supõe-se que a existência desses sentimentos positivos relacionados à cidade de Fortaleza deva-se principalmente ao fato de ter sido este lugar durante muito tempo um referencial para a entrevistada, além da presença de elementos pertencentes ao local que interessam à Rosa.

A cidade de origem da entrevistada comporta aspectos e características que agradaram e foram formadores da identidade de Rosa. Segundo Mourão e Cavalcante (2011), a identidade de lugar funciona como uma subestrutura da categoria de identidade, a qual é vista como um conceito mais amplo, pois se apresenta de forma multifacetada e é influenciada por um conjunto de elementos de ordem biológica, psicológica, social, entre outros, que são próprios da pessoa e da representação que ela tem de si mesma. Seus elementos mostram-se sempre em interações entre o próprio indivíduo e modificações ao longo da vida.

É possível perceber no relato de Rosa sobre sua cidade de origem trechos de fatos importantes que contribuíram, de alguma forma, na pessoa que "está sendo" hoje. Percebe-se que atualmente não existe essa proximidade física ou desejo de retorno a sua cidade. Porém, a existência da identidade de lugar pode ocorrer em um tempo e lugar que esteja presente na memória do sujeito e relembrado sempre que for evocado.

Assim sendo, a identidade de lugar está relacionada tanto aos aspectos temporais como aos espaciais, e não se limita à presença do sujeito no local para que ocorra (MOURÃO \& CAVALCANTE, 2011), como, aparentemente, é o caso de dona Rosa, que mantém o processo de identidade de lugar com Fortaleza na memória através de um tempo e local específico, considerando todas as influências desse ambiente que colaboraram para o desenvolvimento de identidade própria e identidade de lugar.

De acordo com Mourão e Cavalcante (2011), os lugares de vivências do sujeito tornam-se significativos para ele e se constituem elementos importantes na construção de sua identidade. Dona Rosa viveu em Fortaleza até aproximadamente os seus 18 anos. A sua cidade natal torna-se um dos aspectos mais relevantes na construção de sua identidade e 
elaboração de uma identidade de lugar, pois foi na convivência nesse ambiente e com os tipos de relações estabelecidas que esse processo identitário foi se estruturando.

Segundo os autores supracitados, Korpela (1989, apud MOURÃO \& CAVALCANTE, 2010) apresenta o processo de identidade de lugar como uma estrutura psicológica advinda da relação de identificação do sujeito com o seu ambiente. Assim, possibilita comportamentos no ambiente que criamos e sustentamos, um entendimento de "quem somos". Em vista do que foi apresentado por Rosa, Fortaleza influenciou na orientação de "quem ela é" tomando por base os contextos sociais, culturais e econômicos referentes ao ambiente em que se encontrava.

Vale destacar os autores Twigger-Ross e Uzzell (1996, apud MOURÃO \& CAVALCANTE, 2011) que através do modelo de Breakwell relacionam a identidade e o lugar e para fundamentar esta relação, estabeleceram quatro princípios ou categorias. A primeira categoria, "a distinção", refere-se a uma diferenciação de relação entre um e outro ambiente que a pessoa vivencia. Desta forma, pode-se perceber a relação entre Rosa e sua casa, ambiente familiar, e a praia, ambiente de diversão. Ambos os lugares exigem comportamentos distintos e tem abertura para certas relações, atitudes, cognições que dizem respeito ao ambiente específico e à relação com Rosa.

A segunda categoria é a da "continuidade", que consiste na manutenção de uma lembrança de lugares importantes e de referências do passado para o sujeito. Fortaleza foi um lugar de extrema importância na construção da identidade de Rosa e apesar de não haver o desejo de morar lá novamente, ela expressa elementos mantidos na memória. É importante lembrar que alguns parentes e amigos continuam morando na sua antiga cidade e ela se torna atrativa por permitir esse contato dentre outras coisas. Ela afirma: "O que eu gosto em Fortaleza são as praias, meus sobrinhos, minha irmã, meu cunhado e aquela maresia. Oh, vento gostoso" (MARIA, 2016, p.6). Isto permitiu o processo de identidade de lugar. Dessa forma, a ocupação de um lugar pelo sujeito não acontece apenas para atender as suas necessidades e demandas mas, também, permite uma continuidade do passado e identificação nesse ambiente.

O terceiro princípio diz respeito à "autoestima". Este recebe influência do lugar onde vive o indivíduo, suas experiências e aspectos relacionados a ele. É uma avaliação que a pessoa faz de si e dos grupos que participa a partir da reputação que o ambiente tem. A consciência que a pessoa tem de si mesma e as escolhas que irá fazer são realizadas a partir da influência, compreensão do ambiente e suas relações nele. Rosa relata que sua moradia em Fortaleza era em casa própria, sua mãe trabalhava para sustentar a todos e o bairro em que 

e-ISSN 2016/Atual: 2525-7870 | e-ISSN 2015/2016: 2447-018X

moravam não era próximo das praias. Ela conta que nunca tiveram muito "luxo" e sua mãe sempre se esforçou pra sustentar a todos. Dessa forma, aparentemente, o local em que residiam se encaixava naquilo que eles poderiam conseguir e atendia as demandas e necessidades de toda a família.

Por fim, o principio "eficácia" refere-se à "satisfação" das necessidades e demandas sociais desse sujeito, assim como a facilidade para a resolução de tarefas e interação do indivíduo no ambiente. Fortaleza, no passado, era vista como satisfatória e por isso a relutância em ir morar em outra cidade. Entretanto, atualmente o lugar não atende as demandas e necessidades de Rosa, visto que lá ela não teria a mesma facilidade e elementos na aquisição da casa própria, além outros fatores apontados na entrevista. Exposto o sentimento de Identidade de Lugar em Fortaleza, seguiremos o mesmo processo em Boa Vista.

Cabe salientar que para criação e existência de identidade de lugar é necessário que exista uma representação desse ambiente, pois é a partir da significação dos espaços físicos que o ambiente que não possuí uma representação passará, então, a ter um signo. Este influenciará a subjetividade e segundo Vigotski (1998a, apud PONTE, BONFIM \& PASCUAL, 2009) passa a ser um mediador do comportamento humano e estrutura formadora da subjetividade. O processo de atribuir um signo a um ambiente, às vezes, pode ser causado por um momento de sofrimento ao sujeito, quando este é obrigado pelas circunstâncias a permanecer na presença do mesmo sem sua vontade ou estar cercado por elementos que não atendam suas demandas sociais e/ou necessidades. De acordo com Rosa: "Quando eu cheguei aqui passei três meses chorando querendo voltar, pois só via mato, mato e mato" ou "Olha a adaptação foi difícil. Porque você voltar a tomar água de pote, passar a roupa em ferrinho de brasa" (MARIA, 2016, p.3). Ela expressa que sofreu muito até se adaptar com o ambiente, isto porque ele exigia outros comportamentos e demandas que ela não estava habituada a ter. Além disso, esse ambiente era totalmente desconhecido em termos de território e pessoas conhecidas a ela. As únicas pessoas que ela, geralmente, tinha contato era sua família e teve que aderir a práticas que lhe causavam algum incômodo, aparentemente, como beber água de pote, não ter energia tendo que passar roupa com o ferro de brasa, etc. Assim, Rosa afirma: "Naquele tempo era água de poço, depois ligaram a luz e depois a água" (MARIA, 2016, p.2).

No momento que esse vínculo com a cidade de Boa Vista foi criado, a entrevistada passou a atribuir um significado e sentido ao seu ambiente de convívio. Portanto, o ambiente torna-se portador de um signo para a dona Rosa, permitindo se reconhecer e desconhecer a si mesmo nesse processo e na presença desse ambiente. Vale ressaltar a presença e importância 
da afetividade, pois é através dela e em conjunto com os lugares semióticos que há a possibilidade do desenvolvimento e/ou criação do processo de identidade vinculada ao lugar. Pois este último é construído a partir de uma “[...] relação afetiva e política de significação/apropriação do espaço” (PONTE, BONFIM \& PASCUAL, 2009, p.350).

Esse processo é visível na fala da entrevistada quando expressa: "Aqui é uma cidade boa. Gente boa. Cidade farta" (MARIA, 2016, p.5) após relatar as dificuldades (de ordem emocional, estrutura física do local e outros) enfrentadas desde sua chegada a cidade. Rosa demonstrou que apesar de tudo que passou na cidade de Boa Vista, ela tem um vínculo afetivo com o ambiente que reside por tanto tempo, ela afirma: "Eu não moraria lá novamente [...] Não tem outro lugar que eu imagino para morar, é Boa Vista. Eu já fui a Manaus. Mas não moraria lá também" (MARIA, 2016, p.6). E, em virtude da afetividade com o ambiente, Rosa demostra sua preferência por Boa Vista e não trocaria por outra. Não é que Fortaleza não seja "tão agradável como antes" e sim que Boa Vista atende mais demandas e necessidades do que qualquer outro lugar para ela. Ela demostra ter uma identificação com o ambiente e com alguns processos envolvidos, quando afirma: "Eu já sou roraimense, completamente" (MARIA, 2016, p.8). A entrevistada demonstra, assim, ter além de um vínculo com a atual cidade, uma identificação de lugar também.

Desta forma, através da apropriação e atribuição de sentido/significado dos lugares é possível entender o processo de construção de identidade de lugar. Pois o ambiente se torna lugar na medida em que passa por esses processos, como aconteceu com dona Rosa e a cidade de Boa Vista, visto que ela foi vivenciando e se apropriando do ambiente que residia, o ambiente passou a portar um signo específico a ela e influenciar no processo de identidade de lugar.

Os autores Ponte, Bonfim e Pascual (2009) apresentam um tripé como base que o lugar possui. Ele se apresenta de forma identitária, relacional e histórica. Então, a identidade de lugar se mostra diferente e moldada de acordo com as relações/interações humanas e a visão que se tem de tal área, como acontece com Rosa em relação às duas cidades. Por este motivo, não é possível afirmar que ambos são parecidos ou aconteceu de forma linear.

De acordo com os autores Proshansky, Fabian e Kaminoff (1983, apud MOURÃO \& CAVALCANTE, 2011, p. 210) a identidade de lugar é constituída "por cognições sobre o mundo físico, relativas à variedade e à complexidade dos lugares que contribuíram ou contribuem para a satisfação de suas necessidades [...]”. Ou seja, existe uma relação direta entre o relacionamento do sujeito com o ambiente e a satisfação das suas demandas sociais (necessidades biológicas, psicológicas, sociais e culturais). Partindo desse pressuposto em 
conjunto com as formas de cognições entendidas como "memórias, ideias, sentimentos, atitudes, valores, preferências, [...]” (MOURÃO \& CAVALCANTE, 2011, p. 210) sobre o ambiente físico é, então, desenvolvido esse processo. A identidade de lugar tem a funcionalidade de criar um ambiente interno com sustentação e proteção à autoidentidade desse sujeito e que contribui como base para as transformações da identidade provenientes das mudanças que o ambiente sofre e influencia. Diante disso, pode-se relacionar este processo com as experiências apontadas por Rosa através das suas citações acima, que esboçam além do vínculo afetivo em relação à cidade de Boa Vista, um sentimento de identificação com o ambiente e pertencimento ao local. Percebe-se, ainda, a presença do sentimento de pertencimento, que neste caso intensifica o processo de identidade de lugar.

O sentimento de pertencimento aparece como uma subcategoria da identidade do sujeito, relacionando o sujeito a um ambiente importante para ele. Diante disto, existe um conjunto de percepções cognitivas, vinculação emocional e pertencimento que a pessoa sente relacionado ao ambiente. Assim, o sentimento de pertença configura-se como uma sensação de fazer parte, de conexão com aquele lugar. É estar integrado a ele. Desse modo, esse sentimento permite a percepção da identidade de lugar, pois colabora para a existência desse processo. Quando Rosa expressa ser roraimense, aparentemente demostra que a realidade e as suas vivências, da parte que tem contato com a cidade, lhe permite sentir-se pertencente e, ainda, identificar-se com este lugar, considerando aspectos e os contextos de ordem cultural, social e econômica. A entrevistada afirmou: "Não tem outro lugar que eu imagino para morar" (MARIA, 2016, p.6). Ela demonstra, assim, ter uma vinculação forte com a cidade de Boa Vista resultante de vários elementos que incidem e influenciaram em sua vida e escolhas.

Assim sendo, a identidade de lugar é construída a partir da relação de conexão entre o sujeito e esse espaço, considerando uma identificação com o ambiente e aquilo que ele excita no indivíduo. Porém, essa relação deve ser evidenciada primeiramente por experiências nesse local e o sentimento de pertencimento. Esta ideia está ligada ao tempo de interação nessa relação, satisfação das necessidades e demandas desse sujeito que, em conjunto, possibilitam o desenvolvimento de identidade com o lugar, como é possível identificar através da afirmativa de Rosa: "O que eu gosto aqui é tanta coisa, só o fato de eu ter a minha casa, a minha família". Isto revela que o ambiente permite o sentimento de pertença, o qual promove o processo de identidade de lugar a partir das demandas e necessidades sociais, físicas, emocionais, econômicas, culturais, sociais, dentre outros, e ainda apresenta alguns motivos determinantes na sua permanência na cidade. 
Segundo Mourão e Cavalcante (2011) o sentimento de pertencimento, também aparece juntamente com a identidade de lugar. Ele diz respeito ao sujeito sentir-se integrado, pertencente a um grupo ou categorias específicas a sua identidade. Através das citações anteriores de Dona Rosa, há evidências da existência do sentimento de pertença vinculado ao processo de identidade de lugar referente a cidade de Boa Vista.

Outro processo que aparece nessa relação de Rosa com a sua antiga cidade e a atual é a categoria de apego ao lugar. Primeiramente Giuliani (2004) o apresenta como um laço afetivo criado na relação indivíduo-ambiente e o desejo de estar próximo a esse lugar.

A forma como este apego aparece na fala de Rosa em relação às cidades se estruturam de maneiras diferentes, isto é, em Fortaleza, existe uma vinculação com o ambiente e um desejo de retorno a passeio, pois neste "lugar" existem elementos que atraem a entrevistada. Além disso, existem elementos de vivências e experiências que fazem parte na configuração da identidade de Rosa de hoje, a qual demostra, durante a entrevista, considerar esse ambiente importante, e justifica isso, apresentando elementos presentes em Fortaleza que são relevantes à ela. O sentimento de apego ao lugar, em relação à Fortaleza, se apresenta apenas guardado na memória e não em uma relação de presença do objeto. Neste sentido, é mantido na memória um tempo, local e contex to específico de importância que colaborou na existência de quem ela é atualmente e influenciou na criação de tal sentimento. Desta forma, o apego ao lugar referente à Fortaleza é mantido e configurado através das lembranças do passado e das possibilidades de contato com esse lugar. Observa-se que não há o desejo de retorno com a finalidade de morar, entretanto, sempre que pode vai a passeio e costuma comunicar-se com sua irmã e amigos de lá.

Então, Giuliani (2004) categoriza o sentimento em três processos: 1) O primeiro consiste em uma relação funcional, em que há a satisfação das necessidades da pessoa no ambiente com a presença de componentes cognitivos. O tempo de residência é visto como consequência do apego funcional. Esse aspecto está relacionado diretamente com a satisfação das necessidades desse sujeito, o que em caso de insatisfação, pode interferir de forma negativa a fim de diminuir o sentimento de apego ao lugar (GIULIANI, 2004). De acordo com Rosa: "Aqui todos nós, cada um tem a sua casinha" (MARIA, 2016, p.5). Percebe-se que a casa própria é um dos elementos necessários para a residência na atual cidade em que vive dona Rosa.

2) O segundo aparece como uma representação que esse lugar possui em um nível simbólico e/ou físico relacionado a identidade da pessoa (GIULIANI, 2004), isto é, o local do passado mostra-se importante para o sujeito, ainda que não haja um contato com o mesmo 
e/ou ele exista apenas em memórias ou recordações, como é o caso de Fortaleza para a entrevistada. Ela tem uma relação de utilidade com Fortaleza, pois ela utiliza/usufrui dos elementos, desse ambiente, que são de seu interesse. Enquanto que com Boa Vista, a relação é funcional, pois tem o desejo de permanência. Assim, ela apresenta elementos que permitem a sua permanência na cidade de Boa Vista. Rosa afirma ainda: "Você pensa que lá eu teria a minha casinha? De jeito nenhum" (MARIA, 2016, p.5). Ela demostra, aparentemente, atribuir uma parcela das suas conquistas ao ambiente, considerando que se estivesse em outro local a dificuldade seria maior.

3) $\mathrm{O}$ terceiro aspecto mostra-se relacionado ao período de moradia e familiaridade com o lugar, relacionado com as emoções e representações do ambiente, assim como o sentimento de segurança, conforto e bem estar que o sujeito sente relacionado ao ambiente. $\mathrm{O}$ local é transformado em um "porto seguro" e permite uma base para se viver nele. Esse aspecto é considerado muito importante na velhice, dada a fragilidade que essa fase apresenta e a necessidade de um lugar que tenha tais características. Estar mais apegado em um processo pode dificultar seu apego com outro lugar que vise atender as mesmas funções (GIULIANI, 2004). É possível identificar tal processo através das características citadas acima e em um trecho da fala de dona Rosa: "Eu me sinto segura aqui. Acho aqui calmo, pelo menos onde eu moro. Depois que eu fecho a porta não ouço mais nada. A gente dorme tranquila" (MARIA, 2016, p.9). Esta fala demonstra que os elementos que promovem segurança, conforto e bem estar são essenciais para o desenvolvimento do apego ao lugar e o desejo de estar na presença do mesmo, como é a relação de Rosa com Boa Vista.

Giuliani (2004) aponta alguns critérios como definidores para o processo de apego ao lugar. O primeiro é a permanência do vínculo afetivo da pessoa e o ambiente que, em alguns casos, o sujeito só se dá conta quando esse laço é ameaçado e causa algum desconforto a ele. Este conceito pode ser apontado na vida de Rosa, atualmente, em Boa Vista. Em algum momento durante a entrevista, ela afirma “[...] ]eu não queria vir pra cá” (MARIA, 2016, p.1), demostrando, assim, ter o desejo de permanecer em Fortaleza em um primeiro momento. Enquanto que, atualmente, ela mora cerca de 34 anos em Boa Vista, ou seja, apesar de ter existido uma rejeição em um primeiro momento pela cidade pelo desejo de retornar para a cidade de origem, existem elementos que incitam na entrevistada o desejo de permanecer na cidade de Boa Vista, elementos esses que não atuam apenas no presente, mas no passado e possivelmente no futuro.

De acordo com a hipótese de Feldman (1990, apud GIULIANI, 2004) a categoria "identidade de lugar" pode ser um elemento que colabora no estabelecimento de apego ao 
lugar. Desta forma, a entrevistada que apresenta em uma citação acima sentir-se natural de Roraima, demostra, assim, possuir, neste ambiente, uma relação entre o apego ao lugar e a identidade de lugar.

De acordo, ainda, com Giuliani, Ferrara e Barabotti (2000, apud ELALI \& MEDEIROS, 2011) o apego ao lugar é um processo que exige um desenvolvimento gradual e tem sua relação com o tempo nesse sentido, dependendo de influências importantes como a satisfação das necessidades do indivíduo, a representação desse lugar para ele, o tempo e a familiaridade com o local. Esses aspectos não se excluem, mas se convergem, em algum ponto. Tal ponto está presente na relação de Rosa com ambas as cidades.

A cidade de Boa Vista apresenta características e fatores que contribuíram e contribuem para a permanência da entrevistada neste lugar. Não é que ela não goste de Fortaleza, pois ela tem sentimentos sobre lá. Entretanto, há mais interesse da parte de Rosa em permanecer e motivos para continuar residindo em Boa Vista do que em outro local, demostrando maior sentimento de apego em relação à cidade de Boa Vista. Contudo, apesar de toda experiência que vivenciou em Fortaleza, não voltaria novamente com o intuito de morar lá, limitando, assim, suas idas à cidade apenas para visitar os familiares, amigos e passear. Isto porque apesar de Fortaleza ser uma cidade muito querida para ela, não é um lugar que ela gostaria de morar, pois prefere Boa Vista.

Vale ainda apontar que o apego ao lugar não é um processo estático, uniforme ou limitado. Podendo se caracterizar das mais variadas formas entre o sujeito e o lugar. Rosa, em relação a Fortaleza, aparentemente apresenta esse processo guardado em sua memória e nas oportunidades que tem de visitar a cidade. Para o bom desempenho desse processo de apego ao lugar é necessário considerar a memória do sujeito. Isto porque é através da memória que se tem a possibilidade desse processo, pois é ela que permite a recordação de um fenômeno aproximando o sujeito do passado. É através da lembrança que o sujeito pode manter vivo um vínculo com um lugar importante a ele e que lhe cause satisfação. Dessa forma, o apego ao lugar necessita da memória para se concretizar e pode existir apenas nela, não se limitando a estar presente no ambiente físico.

A memória torna-se uma importante categoria para entender esse processo. Observa-se que a elaboração e análise da história relatada realizam-se a partir da evocação das lembranças. Vale ainda notar que os processos de identidade de lugar e apego ao lugar podem existir apenas em um tempo do passado que é importante à Rosa.

A noção aqui apresentada fundamenta-se na teoria de Halbwachs (2004), o qual diz que para que se haja um contato com o passado, necessita-se de recorrer às lembranças do 
passado. A compreensão que se tem desse evento se apoia sobre a lembrança e experiência que de alguma forma possibilitou o contato do sujeito com o tal fenômeno. Percebe-se, assim, que o relato de Rosa a todo o momento se utiliza das informações que tem acesso referente ao que se passou. Ao lembrarmo-nos do passado, não nos sentimos como antes, pois não somos o mesmo de antes, e esse processo afeta na percepção dos fatos do passado ao serem lembrados (HALBWACHS, 2004). Essa dinâmica acontece com a depoente, pois ela expressa fatos do passado em que a sua percepção atual é diferente da anterior. Rosa, a todo o momento, se utiliza do passado, levando-nos a crer que essas lembranças têm sentimentos que não são como antes e são importantes. Pode-se perceber em sua fala que ela tinha um posicionamento quanto a sua permanência na cidade de Boa Vista que é diferente do atual. Para o teórico supracitado, as lembranças do passado não tem a mesma intensidade. Rosa evoca a todo o momento as lembranças por serem importantes.

A rememoração de algo recebe influência dos signos que aprendemos ao longo da vida, aos quais chamamos de memória coletiva, por dizerem respeito a uma aprendizagem baseada na mediação entre nós mesmos e a coletividade. Por isso, quando nos lembramos de algo, não o fazemos sozinhos, e sim a partir de uma influência direta e constante da memoria coletiva, ou seja, nossas lembranças não são particulares ou partiram apenas de nós, pois surgem a partir do meio social que nos encontramos (HALBWACHS, 2004).

Pode uma pessoa encontrar-se com "algo" do passado? Sim, ela só encontra com o passado a partir da memória. Entretanto, não existe o contato com o objeto (Fortaleza), pois este está diferente daquele guardado em sua memória. Portanto, há um estranhamento do sujeito com esse local. Quando nos encontramos com algo já presenciado no passado há uma sensação de estranhamento, pois todos os sujeitos envolvidos não são os mesmos. É como um caminho que já foi percorrido, porém, ele é "novo" (HALBWACHS, 2004). Tal estranhamento é apontado por Rosa quando afirma que quando retornou a passeio em Fortaleza, a cidade, estava muito diferente. Ela afirma: "Lá em Fortaleza mudou, pois as casas estão todas em cima das outras, está diferente" (MARIA, 2016, p.1).

A lembrança pode ser definida como uma reconstrução do passado com dados emprestados no presente. E para que a memória do outro passe a complementar a nossa, é necessário que os eventos do passado tenham alguma relação de proximidade (HALBWACHS, 2004). O apego ao lugar e a identidade com lugar permite essa proximidade dos eventos vividos em algum momento do passado e em um determinado lugar com o sujeito. 
A concepção cristalizada em princípios, que atualmente não são evidentes em Rosa, no que se refere ao apego ao lugar, pode ser configurado como não existente, uma vez que esse sentimento é mantido pela memória. Dessa forma, a memória possui função fundamental na configuração de tais processos. O estudo analisou o presente de Rosa em relação à cidade de Fortaleza e Boa Vista, assim como a presença dos processos abordados anteriormente. Em Boa Vista foi possível perceber os processos de identidade de lugar, apego ao lugar e sentimento de pertencimento mais consolidados, pois existem fatores que são determinantes na permanência da depoente na atual cidade. Diante disso, esses processos são evidenciados através da fala da depoente e mostram-se de forma intensa e presente na história de Rosa promovendo, ainda, sua permanência na cidade de Boa Vista.

Contudo, a partir das referências bibliográficas buscadas e informações colhidas por meio da entrevista aberta com a depoente Rosa, foi possível compreender a dinâmica e amplitude dos processos que trata o estudo, aplicados a um contexto específico. É importante apontar que nem todas as características desses processos são representadas da mesma forma que descritas, pois estes são multifacetados e amplos no que se referem a sua construção e configuração. Percebe-se que em ambos os processos de identidade de lugar, em Fortaleza e em Boa Vista, aparecem fatores e elementos ora comuns, ora distintos.

Dessa forma, Fortaleza é lembrada com afeição por Rosa, apesar de seu interesse ser restrito à visita de amigos, aos familiares, ao mar e alguns outros elementos que a cidade pode oferecer a ela. Logo, sua relação com esta cidade é de utilidade, pois ela vai para lá a fim de usufruir dos elementos que considerados importantes. A depoente apresenta indícios de que há o processo de identidade de lugar e apego ao lugar em relação a esta cidade. Entretanto, eles se caracterizam de forma distinta dos mesmos processos referentes à Boa Vista. Esses sentimentos são mantidos na memória e o contato se dá por esse caminho. É importante apontar que o sentimento de pertencimento não aparece relacionado à cidade de Fortaleza. Existem evidências nas falas de Rosa sobre a cidade de Boa Vista que esboçam a existência dos processos de identidade de lugar, apego ao lugar e sentimento de pertencimento. Isto acontece por meio da vinculação intensa e presente que a mesma tem com o lugar e em conjunto, existem os motivos determinantes para sua permanência em Boa Vista, tais como a casa própria, a família, a mãe com saúde e moradia própria de cada irmão.

Diante disso, o ambiente onde Rosa mora atende as demandas, necessidades e, também, abre possibilidades a ela que não teria em outro lugar. É importante salientar que existe a presença dos processos de identidade de lugar, apego ao lugar e o sentimento e pertencimento em conformidade com os aspectos apontados na literatura. 
RELACult - Revista Latino-Americana de Estudos em Cultura e Sociedade

Revista Latinoamericana de Estudios en Cultura y Sociedad | Latin American Journal of Studies in Culture and Society V. 02, Ed. Especial, dezembro, 2016, p. 741-756| periodicos.claec.org e-ISSN 2016/Atual: 2525-7870 | e-ISSN 2015/2016: 2447-018X

Deve-se observar a diferença temporal dos processos na vida da entrevistada. Em Boa Vista falamos do tempo atual, apesar da utilização do passado. Enquanto que em relação à Fortaleza, nos remetemos a um tempo específico e guardado na memória de Rosa.

\section{Referências}

ALVES, B. F. Sentimento de comunidade e apego ao lugar: Um estudo correlacional em situação de contradição social. Trabalho de Conclusão de Curso, Boa Vista,Roraima, 2015.

BOSI, E. Memória e Sociedade: Lembranças de velhos. 3. ed. São Paulo: Companhia das Letras, 1994.

BOCK, A. M. B.; FURTADO, O.; TEIXEIRA, M. L. T. Psicologias: uma introdução ao estudo de psicologia. 14 edição. São Paulo: Saraiva, 2008.

CAMPOS-DE-CARVAlHO, M. I.; CAVAlCANTE, S.; NÓBREGA, L. M. A. Ambiente. In: ELALI, G. A.; CAVAlCANTE, S. (orgs) Temas Básicos em Psicologia Ambiental. Petrópolis, RJ: Vozes, 2011.

CARLOS, A. F. A. A cidade. 8 ed. São Paulo: Contexto, 2008.

CAVAlCANTE, S.; Elias, T. F. Apropriação. In: Elali, G. A.; CAVAlCANTE, S. (orgs) Temas Básicos em Psicologia Ambiental. Petrópolis, RJ: Vozes, 2011.

CAVAlCANTE, S.; NÓBREGA, L. M. A. Espaço e Lugar. In: Elali, G. A.; CAVALCANTE, S. (orgs) Temas Básicos em Psicologia Ambiental. Petrópolis, RJ: Vozes, 2011.

ELALI, G. A.; MEDEIROS, S. T. F. Apego ao Lugar. In: ELALI, G. A.; CAVALCANTE, S. (orgs) Temas Básicos em Psicologia Ambiental. Petrópolis, RJ: Vozes, 2011.

FREITAS; S. M. de. História Oral: possibilidades e procedimentos. 2 ed. São Paulo: Associação Editorial Humanistas, 2006.

GIULIANI, M. V. O lugar do apego nas relações pessoas-ambiente. In TASSARA, E. T. O., RABINOVICH, E. P., GUEDES, M. C. (Orgs.). Psicologia e ambiente. São Paulo: EDUC, 2004.

HALBWACHS, M. A memória coletiva. - São Paulo: Centauro, 2004.

LIMA, D. M. A.; BOMFIM, Z. Á. C. Vinculação afetiva pessoa-ambiente: diálogos na psicologia comunitária e psicologia ambiental. PSICO, Porto Alegre, PUCRS, v.40, n. 4, pp. 491-497, out/dez. 2009.

LYNCH, K. A imagem da Cidade. São Paulo : Martins Fontes, 1997. 
MARIA, R. Entrevista I. [mar. 2016]. Entrevistadores: NEVES, L. R. e MACÊDO, L. A. BOA VISTA: UFRR-RR, 2016. 1 arquivo .mp3 (50 min.). Entrevista concedida ao Projeto de Iniciação Científica desenvolvido na UFRR.

MOURÃO, A. R. T.; CAVAlCANTE, S. Identidade de Lugar. In: ELALI, G. A.; CAVAlCANTE, S. (orgs) Temas Básicos em Psicologia Ambiental. Petrópolis, RJ: Vozes, 2011.

NEVES, L. R. Psicossociologia urbana: Catástrofe socioambiental de enchente - Um estudo de caso. Curitiba: Juruá, 2016.

PONTE, A. Q.; BONFIM, Z. Á. C.; PASCUAL, J. G. Considerações Teóricas sobre identidade de Lugar à luz da abordagem histórico-cultural. Psicol. Argum., 27(59), 345354, Out/Dez. 2009.

TUAN, Y. F. (1930) Espaço e Lugar: A perspectiva da experiência. [Tradução: Lívia de Oliveira] - Londrina: Eduel, 2013. 